\title{
BOND STRENGTH AND INTERFACIAL MORPHOLOGY EVALUATION OF SELF-ADHERING FLOWABLE COMPOSITES
}

\author{
Nabawy A. Alrobeigy* and Yasser A. Abed ${ }^{* *}$
}

\begin{abstract}
Objectives: To evaluate the micro-shear bond strength ( $\mu \mathrm{SBS})$ and interfacial morphology to dentin of self-adhering flowable composites (SAFCs) in comparison to a combination of all-in-one adhesive and conventional flowable composite (CFC).

Materials and Methods: Forty prepared adult tooth dentin surfaces were randomly divided into 4 groups $(\mathrm{n}=10)$ according to adhesive and/or flowable composite material applied: group I: Dyad Flow (SAFC; Kerr, USA); group II: Fusio Liquid Dentin (SAFC; Pentron Clinical, USA); group III: Vertise Flow (SAFC; Kerr, USA); group IV: OptiBond All-In-One (Kerr) + Premise Flowable (CFC, Kerr, USA). Composite micro-specimens of each group were prepared on dentin surfaces according to manufacturer's instructions, then stored in distelled water $\left(37{ }^{\circ} \mathrm{C}, 24 \mathrm{~h}\right.$.) before $\mu \mathrm{SBS}$ testing. For interfacial morphology evaluation, mesial and distal class II slots were prepared in each of 16 teeth, then each group $(n=4)$ were restored with its respective composite. Each specimen was sectioned mesio-distally and prepared for interface evaluation by SEM. $\mu$ SBS data were analyzed using one-way ANOVA, followed by Tukey test.
\end{abstract}

Results: Each of the Self-adhering flowable composites (group I, II, and III) recorded $\mu \mathrm{SBS}$ value that was statistically comparable to that measured by a combination of all-in-one adhesive and conventional flowable composite (group IV). Also, there were no significant differences ( $p>0.05$ ) in $\mu$ SBS among Self-adhering flowable composite materials. SEM images showed that all materials exhibited a continuous interface and appeared well-adapted to dentin.

Conclusions: All Self-adhering flowable composites tested achieved satisfactory $\mu$ SBS and marginal adaptation to dentin substrate.

KEYWORDS: Flowable composite; Self-adhering; All-In-One adhesive; Micro-shear bond strength; SEM.

* Assistant Professor, Department of Dental Biomaterials, Faculty of Dentistry, Tanta University, Egypt.

** Lecturer, Department of Operative Dentistry, Faculty of Dentistry, October 6 University, Egypt. 


\section{INTRODUCTION}

A dramatic improvement in resin composite formulation and adhesive technology has occurred since the initial introduction of resin composite in 1960s. Numerous efforts have been focused on dentin and bonding systems in the last two decades to achieve a durable bonding mechanism. ${ }^{(1)} \mathrm{High}$ and stable bonding of resin composites to tooth structure substrates is critical for obtaining marginally sealed and durable restorations. ${ }^{(2)}$ Simplification has been a principal in the research advancement of dental adhesives not only to facilitate procedures, but also to reduce handling errors and technique sensitivity. ${ }^{(3,4)}$ These advancements and efforts has led to the introduction of all-in-one adhesive systems. ${ }^{(1,5-12)}$ These systems is established on selfetch mechanism which is relied on acidic resin monomer for simultaneous demineralization and resin infiltration of the substrate. ${ }^{(2,13)}$ The elimination of separate etching, rinsing, and drying steps in all-in-one systems is an advantageous from the clinical standpoint, since the possibility of cavity contamination is minimized, ${ }^{(14)}$ over wetting and over drying are lessened, ${ }^{(15)}$ and the risk of postoperative sensitivity is reduced. ${ }^{(13)}$ In addition, the bonding procedure is simplified and chair time is saved. ${ }^{(16)}$

Flowable resin composites were first introduced in the late $1996^{(17)}$ with two particular properties: low modulus of elasticity and increased flowability and wettability. ${ }^{(18)}$ Low modulus of elasticity help to relief polymerization shrinkage stresses and consequently preserve marginal integrity, ${ }^{(19-21)}$ while increased flowability and wetting results in an intimate contact with the floor and walls of the cavity leading to improved marginal adaptation. ${ }^{(12,23)}$ On the other hand, it is generally accepted that flowable resin composites has inferior mechanical properties in comparison to conventional composites due to their lower filler load. ${ }^{(21,24-26)}$ Therefore, flowable composites have been recommended to be used as restorative material in low stress-bearing areas and in situations where access is difficult or deep penetration is essential such as: small class III and class $\mathrm{V}$ restorations, small cavities where most of the occlusal forces resisted by remaining tooth structure, enamel defect repair, incisal edge repair, porcelain repair, crown margin or composite defect repair, and pit and fissure sealing; while it is suggested to be used only as cavity liner in restorations of cavities in high stress-bearing areas. ${ }^{(18,25,27)}$

With passing of time and as a result of continuing efforts to simplify daily clinical treatment procedures and to decrease handling errors, a new category of flowable composites, the so-called selfadhering flowable resin composite was introduced that combines the properties of self-adhesion and flowability. ${ }^{(28)}$ Restorations with these composites eliminate the need of etching and bonding steps that normally required for bonding a conventional flowable composites to enamel and dentin. ${ }^{(2)}$ Due to the rapid progress in the categories of self-etch adhesives and resin composites and since it has been reported that the performance of these new materials is product-dependent to a significant extent, ${ }^{(29)}$ it becomes essential to expose the newly introduced materials to laboratory investigations that present data with a predictive value of clinical outcome. ${ }^{(30)}$ Among laboratory tests, bond strength tests are widely used to provide a quantitative measurement of materials adhesion based on the concept that the stronger the bond, the better it will resist the polymerization shrinkage and functional stresses at interface.(6) Marginal adaptation and sealing ability of adhesive materials are among properties of significant clinical relevance. ${ }^{(30)}$ It was reported that insufficient sealing and marginal leakage cause bacterial invasion, leading to secondary caries and pulpal damage.(1)

To the best of our knowledge, there is limited documentation, in the literature, regarding bond strength and marginal adaptation of new selfadhering flowable composites. The present study aimed to investigate the micro-shear bond strength and interfacial morphology to dentin of newly introduced self-adhering flowable composites in 
comparison to a combination of all-in-one adhesive and conventional flowable composite. The tested null hypothesis was that similar bond strength and interfacial morphology to dentin are obtained by the new self-adhering flowable composites and by all-in-one adhesive used in combination with the conventional flowable composite.

\section{MATERIALS AND METHODS}

Three self-adhering flowable composites and one conventional flowable composite with its all-in-one adhesive were used in this study. The materials used as well as their manufacturers, types, compositions, and application procedures are listed in table 1 . The shade of all composites used was A3.
A total of fifty six extracted, non- carious human molars were collected for this study. Teeth were cleaned and stored in $0.5 \%$ chloramine solution at $4^{\circ} \mathrm{C}$ for not more than two months until used in the study. Forty teeth were used for $\mu$ SBS test. The remaining sixteen molars reserved for SEM evaluation of interfacial morphology.

\section{Micro-shear bond strength test}

The forty molars intended for $\mu \mathrm{SBS}$ test were embedded in self-curing acrylic resin (Acroston, Egypt) up to $1 \mathrm{~mm}$ below the cemento-enamel junction with their long axis perpendicular to the base of resin cylinder. Then, occlusal segment of the crown of each embedded tooth was removed

TABLE (1) Chemical compositions and application modes of the materials used in the study

\begin{tabular}{|c|c|c|c|}
\hline Material & Type* & Composition* & Application* \\
\hline $\begin{array}{l}\text { Dyad Flow (Kerr, } \\
\text { Orange, CA, } \\
\text { USA) }\end{array}$ & $\begin{array}{l}\text { Self-adhering } \\
\text { flowable } \\
\text { composite }\end{array}$ & $\begin{array}{l}\text { Matrix: GPDM, HEMA, methacrylate co- } \\
\text { monomers } \\
\text { Filler: PPF, barium glass }(1 \mu \mathrm{m}) \text {, nano silica } \\
\text { filler }(10-40 \mathrm{~nm}) \text {, nano ytterbium fluoride ( } 40 \\
\mathrm{~nm}) .(70 \% \mathrm{wt})\end{array}$ & $\begin{array}{l}\text { Dispense first layer }<0.5 \mathrm{~mm} \text { thick on } \\
\text { a forcefully dried surface; brush with } \\
\text { moderate pressure for } 15-20 \mathrm{sec} \text {; light } \\
\text { cure for } 20 \mathrm{sec} \text {; apply a second layer } 1.5 \\
\text { mm thick; light cure for } 20 \mathrm{sec} \text {. }\end{array}$ \\
\hline $\begin{array}{l}\text { Fusio Liquid } \\
\text { Dentin (Penetron, } \\
\text { Wallingford, CT, } \\
\text { USA) }\end{array}$ & $\begin{array}{l}\text { Self-adhering } \\
\text { flowable } \\
\text { composite }\end{array}$ & $\begin{array}{l}\text { Matrix: 4-META, HEMA, UDMA, TEGDMA } \\
\text { Filler: Nano-sized amorphous silica, barium } \\
\text { glass }(65 \% \mathrm{wt})\end{array}$ & $\begin{array}{l}\text { Dispense first layer } 1 \mathrm{~mm} \text { thick on a } \\
\text { briefly dried surface; agitate for } 15-20 \\
\mathrm{sec} \text {; light cure for } 20 \mathrm{sec} \text {; apply a second } \\
\text { layer } 1 \mathrm{~mm} \text { thick; light cure for } 20 \mathrm{sec} \text {. }\end{array}$ \\
\hline $\begin{array}{l}\text { Vertise Flow } \\
\text { (Kerr, Orange, } \\
\text { CA, USA) }\end{array}$ & $\begin{array}{l}\text { Self-adhering } \\
\text { flowable } \\
\text { composite }\end{array}$ & $\begin{array}{l}\text { Matrix: GPDM, HEMA, methacrylate co- } \\
\text { monomers } \\
\text { Filler: PPF, barium glass }(1 \mu \mathrm{m}) \text {, nano silica } \\
\text { filler }(20 \mathrm{~nm}) \text {, nano ytterbium fluoride ( } 40 \\
\mathrm{~nm}) .(70 \% \mathrm{wt})\end{array}$ & $\begin{array}{l}\text { Dispense first layer }<0.5 \mathrm{~mm} \text { thick on } \\
\text { a forcefully dried surface; brush with } \\
\text { moderate pressure for } 15-20 \mathrm{sec} \text {; light } \\
\text { cure for } 20 \mathrm{sec} \text {; apply a second layer } 1.5 \\
\text { mm thick; light cure for } 20 \mathrm{sec} \text {. }\end{array}$ \\
\hline $\begin{array}{l}\text { Permise Flowable } \\
\text { (Kerr, Orange, } \\
\text { CA, USA) }\end{array}$ & $\begin{array}{l}\text { Conventional } \\
\text { flowable } \\
\text { composite }\end{array}$ & $\begin{array}{l}\text { Matrix: Ethoxylated bis-DMA, TEGDMA, } \\
\text { organophosphate dispersant } \\
\text { Filler: PPF, barium glass }(0.4 \mu \mathrm{m}) \text {, nano silica } \\
\text { filler }(20 \mathrm{~nm}) .(72.5 \% \mathrm{wt})\end{array}$ & $\begin{array}{l}\text { Apply } 2 \mathrm{~mm} \text { thick layer; light cure for } \\
20 \mathrm{sec} \text {. }\end{array}$ \\
\hline $\begin{array}{l}\text { OptiBond All- } \\
\text { In-One (Kerr, } \\
\text { Orange, CA, } \\
\text { USA) }\end{array}$ & $\begin{array}{l}\text { One step self- } \\
\text { etch adhesive }\end{array}$ & $\begin{array}{l}\text { GPDM, HEMA mono and di-functional } \\
\text { methacrylate monomers, nanofillers including } \\
\text { sodium hexafluorosilicate, water, acetone, } \\
\text { ethyl alcohol, photoinitiators }\end{array}$ & $\begin{array}{l}\text { Apply first coat and brush with scrubbing } \\
\text { motion for } 20 \mathrm{sec} \text {; apply a second coat } \\
\text { and brush with scrubbing motion for } 20 \\
\text { sec; air dry gently for } 5 \mathrm{sec} \text {; light cure for } \\
10 \mathrm{sec} \text {. }\end{array}$ \\
\hline
\end{tabular}

GPDM: glycerol phosphate dimethacrylate; HEMA: hydroxyethyl methacrylate; PPF : prepolymerized filler; 4-META: 4-methacryloxyethyl trimillitic acid; UDMA: urethane dimethacrylate; bis-DMA: bisphenol-A-dimethacrylate; TEGDMA: triethylene glycol dimethacrylate. 
using a water-cooled diamond saw (Isomet 1000, Buehler Ltd, Lake Bluff, IL, USA) to expose a flat mid coronal dentin. To obtain standardized smear layers, dentin surfaces were then polished on wet 600-grit silicon carbide paper for $60 \mathrm{sec}$.

The prepared teeth were randomly divided into four groups $(n=10)$ according to the adhesive and/ or flowable composite material applied: group I, Dyad Flow; group II: Fusio Liquid Dentin; group III, Vertise Flow; group IV, OptiBond All-In-One adhesive and Permise Flowable.

The dentin surface was washed thoroughly with water spray and air dried without desiccation according to the manufacturer's instructions. Polyethylene tubes (Tygon Medical Tubing Formulations, Akron, OH, USA) with $1.2 \mathrm{~mm}$ internal diameter and $2 \mathrm{~mm}$ height were used to hold and build-up composite cylinders on dentin surfaces. The tested flowable composite materials were applied directly on the dentin surfaces except for group IV, where OptiBond All-In-One adhesive was applied first before composite application. All materials applied following the manufacturer's instructions (Table 1) and photo cured using LED Blue phase C8 curing unit (Ivoclar Vivadent AG, Schaan, Liechtenstein, Germany) with $850 \mathrm{Mw} / \mathrm{cm}$ output. The output intensity of the curing unit was verified after every ten exposures. All specimens were prepared by the same operator. After light polymerization, the tubes was carefully removed from the composite cylinders with a sharp blade, then each dentin-composite interface was checked with a magnifying lens (Q Optics, Dentaltown L.L.C., Phoenix, USA) at X5 magnification and defective samples were excluded. The specimens were stored in distilled water for 24 hours at $37{ }^{\circ} \mathrm{C}$ before $\mu$ SBS testing.

Each acrylic embedded tooth with its own bonded composite micro-cylinders was secured with tightening screws to the lower fixed compartment of a testing machine (Model LRX-plus; Lloyd
Instruments Ltd., Fareham, UK) with a load cell of $5 \mathrm{KN}$. A loop prepared from an orthodontic wire (0.014 inch diameter) was wrapped around the bonded composite micro-cylinder as close as possible to its base and aligned with the loading axis of the upper movable compartment of the testing machine. A shearing load with tensile mode of force was applied at a crosshead speed of 0.5 $\mathrm{mm} / \mathrm{min}$ until failure occurred. The load at failure (N) was divided by bonding area $\left(\mathrm{mm}^{2}\right)$ to calculate the bond strength in $\mathrm{MPa}$. Failure modes were evaluated under a light stereomicroscope(Olympus SZ 6045 TR Zoom, Olympus Optical Co, Osaka, Japan) at X20 magnification by a single operator and classified as adhesive (if it occurred at dentin/ adhesive or material interface), cohesive (if it occurred in material or dentin) or mixed (if adhesive and cohesive fractures occurred concurrently).

\section{Interfacial morphology}

Sixteen molars were used to evaluate the interface between the resin composites and dentin by SEM. The occlusal surfaces were ground flat at the level of marginal ridges under water coolant to obtain a flat surface that was $4 \mathrm{~mm}$ above the cement-enamel junction and perpendicular to the long axis of the tooth. Class II slots were prepared on the mesial and distal surfaces using carbide bur \# C21 (Jota, Swiss dentistry) mounted in a high-speed water cooled handpiece. The cavity preparation dimensions were: $3 \mathrm{~mm}$ width, $4 \mathrm{~mm}$ length (at the cement-enamel junction) and $1.5 \mathrm{~mm}$ depth. The prepared teeth were randomly divided into four groups $(n=4)$ and the slots of each group were restored with its respective flowable composite, according to the manufacturer's instruction, as done in $\mu \mathrm{SBS}$ test. Then the restored molars were sectioned mesio-distally into two halves using a diamond disk with copious water spray obtaining 8 interface sections for each group. After sectioning procedures, the samples were immersed in $6 \mathrm{~mol} / \mathrm{L} \mathrm{HCL}$ for 30 seconds; to dissolve the mineral component of dentin; rinsed, then they were 
immersed in $1 \%$ NaOCL for 10 minutes to remove any non-infiltrated demineralized dentin matrix (collagen fibers and other organic parts of dentin) or unpolymerized resin. The specimens sections were washed with a copious amount of water and left to dry for 24 hour. This methodology was followed according to Nakabayashi and Takarada. ${ }^{(31)}$ After that, each section was gold sputtered and examined under SEM (JEOL, JSM T330, Japan). Micrographs were taken on specimens sections showing the restoration-tooth interface.

\section{Statistical analyses}

Data analysis of micro-shear bond strength was performed in several steps. Initially, descriptive statistics were done for each group results. As data passed normality test so parametric one way ANOVA followed by pair-wise Tukey's post-hoc tests were performed to detect significance among groups. Chi square test was done for comparison of different failure modes. Statistical analysis was performed using Aasistat 7.6 statistics software for Windows. $P$ values $\leq 0.05$ are considered to be statistically significant in all tests.

\section{RESULTS}

\section{Micro-Shear bond strength}

Means and standard deviations of micro-shear bond strength values are given in table 2 and displayed in figure 1. It was found that group III recorded the highest $\mu$ SBS mean value $(19.6 \pm 4.21$ $\mathrm{MPa})$ followed by group I $(16.08 \pm 2.33 \mathrm{MPa})$, then group IV $(15.71 \pm 3.36 \mathrm{MPa})$, whereas group II recorded the lowest $\mu \mathrm{SBS}$ mean value $(14.58 \pm 4.621$ $\mathrm{MPa})$. The differences either between each of the self-adhering composites (group I, II, and III) and group IV, or among self-adhering composites were statistically non-significant ( $p>0.05$ ) as revealed by one way ANOVA test followed by pair-wise Tukey's post-hoc test.
TABLE (2) Descriptive statistics of the micro-shear bond strength to dentin

\begin{tabular}{ccccc}
\hline Groups & Materials & $\begin{array}{c}\text { Mean } \\
\text { (MPa) }\end{array}$ & $\begin{array}{c}\text { Standard } \\
\text { deviation }\end{array}$ & $\begin{array}{c}\text { ANOVA } \\
\text { (P value) }\end{array}$ \\
\hline I & Dyad Flow & $16.08^{\mathrm{A}}$ & 2.33 & \\
II & $\begin{array}{c}\text { Fusio Liquid } \\
\text { Dentin }\end{array}$ & $14.58^{\mathrm{A}}$ & 4.62 & 0.1142 \\
& & & $(\mathrm{NS})$ \\
III & Vertise Flow & $19.60^{\mathrm{A}}$ & 4.21 & \\
IV & $\begin{array}{c}\text { OptiBond All-In-one } \\
\text { + Permise Flowable }\end{array}$ & $15.71^{\mathrm{A}}$ & 3.36 & \\
\hline
\end{tabular}

Same superscript letters label statistically not significant differences $(P>0.05)$. NS: not significant

\section{Mode of failures}

The frequent distribution (\%) of failure modes are presented in table 3 and showed in figure 2. It was shown that the predominant failure pattern for all groups was the adhesive failure. However, the material with the highest $\mu$ SBS mean value (group III) exhibited the higher percentages of mixed and cohesive failure modes and the material with the lowest $\mu$ SBS mean value (group II) recorded the highest percentage of adhesive failure mode. There were no statistically significant differences among failure modes of all groups as indicated by Chi square test $(\mathrm{p}>0.05)$.

\section{Interfacial morphology}

Scanning electron micrographs showed that all the materials exhibited a continuous interface and appeared well-adapted to the dentin substrate (Fig. 1). However a deeper resin infiltration was observed in Dyad Flow (Fig. 1a) and Vertise Flow (Fig. 1c). A clear, well-defined resin-impregnated layer of dentin was seen in OptiBond All-In-One adhesive image (Fig. 1d), with a minute gaps at the resin-composite interface were also visible. On the other hand, minimal short resin tags were observed in Fusio Liquid Dentin image (Fig. 1b), but the junction between this material and dentin appeared tight. A distinct thin hybrid layer was observed in all images of the tested specimens except for Fusio Liquid Dentin (Fig. 1b), where no definite hybrid layer can be seen. 
TABLE (3) Frequent distribution (\%) of failure modes for all materials tested

\begin{tabular}{clcccc}
\hline \multirow{2}{*}{ Groups } & \multicolumn{1}{c}{ Materials } & \multicolumn{3}{c}{ Failure modes } & Chi square \\
\cline { 3 - 5 } & & Adhesive & Cohesive & Mixed & (P value) \\
\hline I & Dyad Flow & 60 & 0 & 40 & \\
II & Fusio Liquid Dentin & 80 & 0 & 20 & 0.1596 \\
III & Vertise Flow & 50 & 10 & 40 & (NS) \\
IV & OptiBond All-In-One + Permise Flowable & 70 & 0 & 30 & \\
\hline
\end{tabular}

\section{NS: not significant}

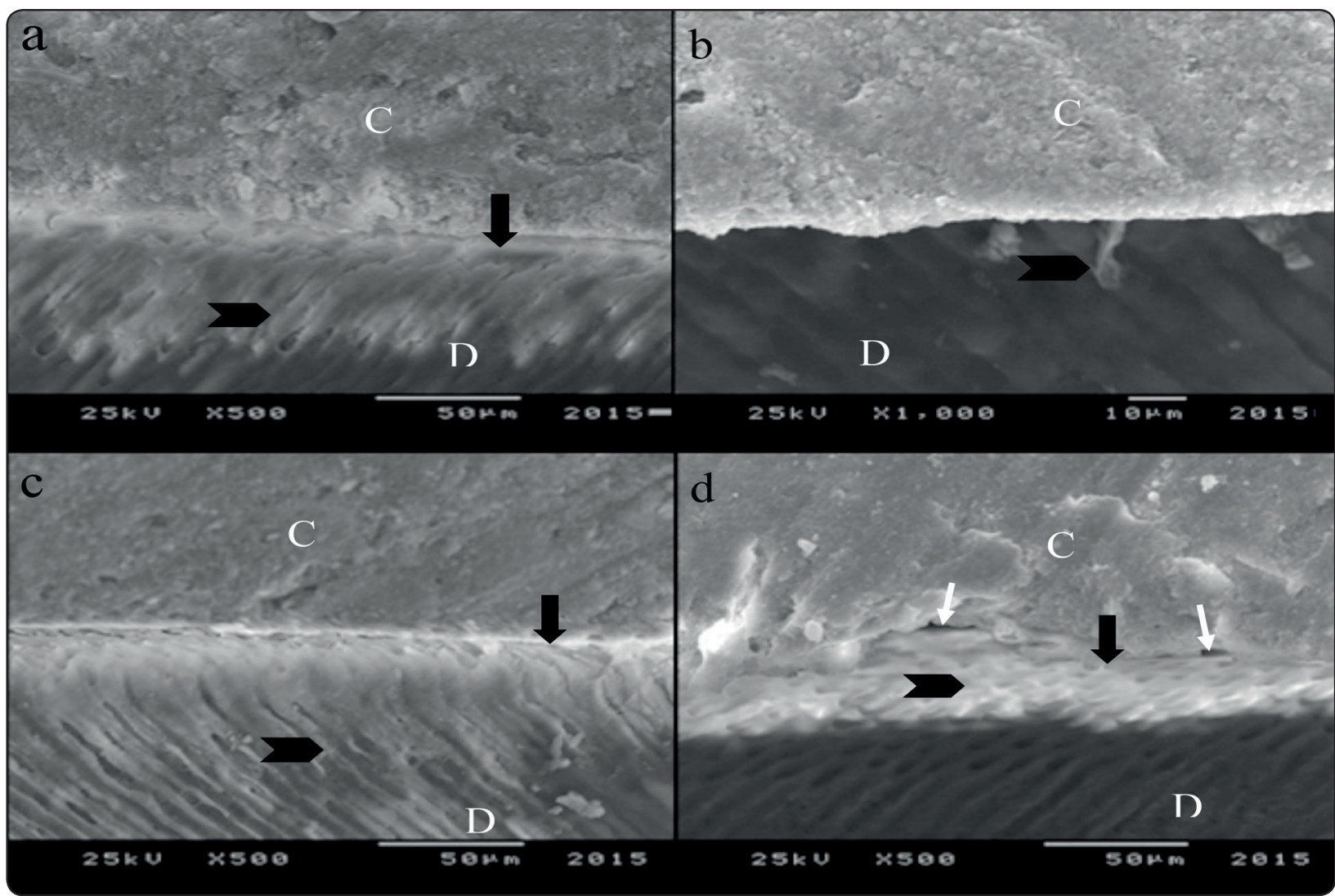

Fig (1) Representative scanning electron microscopy images of the dentin-adhesive/material interface. (a) Dyad Flow, (b) Fusio Liquid Dentin, (c) Vertise Flow, (d) OptiBond All-In-One + Permise Flowable. C: Composite resin, D: Dentin. The chevrons indicate resin-impregnated dentinal tubules. The black arrows point out hybrid layers. The white arrows point to minute gaps at adhesive-composite interface.

\section{DISCUSSION}

Recent research advancements has mainly aimed at reducing technique sensitivity and chair time..$^{(3,4,13,16)}$ From this point of view, the elimination of a bonding step can be considered a great breakthrough. Therefore, it seemed reasonable to consider the all-in-one adhesive followed by the application of conventional flowable composite as the comparative product group for this newly developed self-adhering flowable resin 
composites.(2) According to the findings of this study, the formulated null hypothesis has not to be rejected, since the $\mu \mathrm{SBS}$ values of all self-adhering flowable composites were not significantly different from that of conventional flowable composite bonded with all-in-one adhesive. Also, all materials showed similar marginal adaptation.

Many factors can influence the bonding performance of adhesive systems to dentin, among these are: dentin substrate, ${ }^{(32)}$ dentin treatment, ${ }^{(33)}$ and chemical composition of the adhesive systems. ${ }^{(34)} \quad$ All-in-one adhesive systems are currently composed of hydrophilic and hydrophobic monomers and solubilized in water and/or organic solvents, such as acetone or ethanol. Such monomers can penetrate the smear layer and perform a mild demineralization of the underlying dentin, forming covalent bonds with the dentin collagen and ionic bonds with hydroxyapatite. ${ }^{35,36)}$

Self-adhering flowable composite materials used in this study have different acidic functional monomers. Vertise Flow and Dyad Flow relies on glycerol phosphate dimethacrylate (GPDM) as a functional monomer. GPDM adhesive monomer has an acidic phosphate functional group for etching and bonding to tooth structure. It also has two methacrylate functional groups which copolymerize with other methacrylate monomers to form crosslinked polymeric network and to provide increased crosslinking density and enhanced mechanical strength of polymerized adhesive. ${ }^{(37,38)}$ According to the manufacturers, these materials bonds to tooth structures by two means: firstly through the chemical interaction between the phosphate functional group of GPDM monomer and calcium ions of tooth structure; and secondly through micromechanical bonding as a result of an interpenetrating network formed between the polymerized monomer and collagen fibers (as well as smear layer) of dentin. Micromechanical etching of tooth structure by Vertise Flow and Dyad Flow is facilitated by low
(1.9) $\mathrm{pH}$ of the resin material, which is similar to that of mild self-etch adhesives. ${ }^{(38)}$ However, the bonding mechanism of Fusio Liquid Dentin, is based on 4-methacryloxyethyl trimellitic acid (4META). Fusio Liquid Dentin's unique formula is both acidic (pH 3-4) and hydrophilic, which allows the negatively charged carboxylic acid groups of the methacrylate monomers bond to the mineral ions in the tooth structure. As the carboxylic acid groups are neutralized and the monomers polymerized they become incorporated into the dentin surface enhancing both dentin bonding and sealing ability. (39) Whereas the bonding mechanism of OptiBond All-In-One adhesive is similar to that of Vertise Flow and Dyad Flow, since it also includes GPDM as a functional monomer in its structure. ${ }^{(40)}$

A distinctive characteristic of all self-adhering flowable composites and OptiBond All-In-One adhesive used in the present study is the inclusion of hydroxyethyl methacrylate (HEMA) in their chemical formulations. HEMA is a hydrophilic, water-soluble methacrylate priming monomer that enhances the wetting capability of the adhesive solutions. In addition, HEMA prevents phase separation reactions, by promoting the miscibility of hydrophilic and hydrophobic components of the adhesive. ${ }^{(8,31)}$ Furthermore, it was reported that the inclusion of HEMA in the composition of allin-one adhesives contributed to enhanced 24-hours bond strength. ${ }^{(41)}$ In another previous study, ${ }^{(42)}$ it was pointed out that the lack of HEMA was suggested as a possible explanation for the relatively weak adhesion. Consequently, the inclusion of the same self-etch adhesive monomer (GPDM) in Dyad Flow, Vertise Flow, and OptiBond All-In-One adhesive (groups I, III, and IV) might account for the comparable values of $\mu \mathrm{SBS}$ of these materials that were obtained in this study. Also, from the results of this study, it can be speculated that the similarity in mode of action of 4-META and GPDM functional monomers might explain the insignificant difference in $\mu$ SBS between Fusio Liquid Dentin (group II) 
and OptiBond All-In-One adhesive (group IV). It has been reported that 4-META has a good chemical bonding potential to hydroxyapatite, ${ }^{(43)}$ which also might be the reason for the insignificant difference in $\mu \mathrm{SBS}$ between group II and group IV. The results in the present study are in line with the results of a previous study. ${ }^{(4)}$ The authors repotted that Dyad Flow achieved an equal or higher bond strength to dentin in comparison to that obtained by a separate self-etch adhesives combined with traditional flowable composites. Contrary to our results, Tuloglu et al. ${ }^{(45)}$ found that the shear bond strength of Vertise Flow self-adhering flowable composite was lower than that of Filtek Ultimate conventional flowable composite bonded with OptiBond All-InOne. This difference may be related to the variation in aging procedure. In that previous study, SBS was assessed after thermal aging, while in the present study $\mu$ SBS was measured after 24 hours without considering aging.

In respect to interfacial morphology that was revealed by SEM observations, all tested materials appeared well adapted to dentin. Our results are in line with the results of a previous investigation ${ }^{(2)}$ concerning Vertise Flow and ObtiBond All-InOne. In that study, it was stated that hygroscopic expansion and relatively low polymerization contraction might be advocated as possible reasons for satisfactory sealing performance. In another researches ${ }^{(46,47)}$ it has also been demonstrated that Vertise Flow undergoes hygroscopic expansion. As to hygroscopic expansion, it is documented that acidic resin monomers absorb higher water than neutral resin monomers. ${ }^{(48,49)}$ Recently, Wei et al., ${ }^{(46)}$ pointed out that Vertise Flow has a higher hygroscopic expansion than UDMA-based polymers due to the hydrophilic acid phosphate group and the spacer group in GPDM monomer. Hence, it can be supposed that the hygroscopic expansion of selfadhering flowable composites used in the present study might have participated to the satisfactory marginal adaptation showed by the materials if it is actually equalized polymerization shrinkage. Vichi et al., ${ }^{(2)}$ reported that the acceptable sealing performance showed by Vertise Flow in their study can also be related to the uniqueness of the dynamics in its adhesion/polymerization process. During restoration procedure of conventional resin composite materials, the bonding agent and the restorative composite are placed in sequence, therefore the restorative composite polymerization occurs after bonding is achieved. The bond that just created by the adhesive with the dental substrate may be inhibited by the polymerization stress of the restorative composite. ${ }^{(50)}$ However, In case of self-adhering composite Vertise Flow, bonding and polymerization of the resin occur concurrently.(2) The authors speculated that as the viscous-elastic flow can occur simultaneously with the bonding process, competition between bonding and polymerization stress is decreased, thus promoting marginal adaptation of the material. Consequently, such behavior; in addition to, hygroscopic expansion might be accounted for the meticulous marginal adaptation appeared by all tested materials in the present study, which might in turn also have a positive reflection on bond strength.

Although a well-defined resin-impregnated dentinal tubules layer was observed in SEM image (Fig. 1d) of OptiBond All-In-One adhesive, a more deeper resin infiltrations was evident in the images (Fig 1a and 1c) of Dyad Flow and Vertise Flow, whereas minimal short resin infiltrations without distinct hybrid layer could be seen in the image (Fig 1b) of Fusio Liquid Dentin. The possible explanation for such performances could be attributed to the difference in the acidity $(\mathrm{pH})$ between these materials, where the acidity ( $\mathrm{pH} 1.9$ ) of Vertise Flow and Dyad Flow ${ }^{(37,38)}$ is higher than the acidity $(\mathrm{pH} 2.5)$ of OptiBond All-In-One adhesive, ${ }^{(40)}$ which in turn is higher than the acidity ( $\mathrm{pH} \mathrm{3-4)} \mathrm{of} \mathrm{Fusio} \mathrm{Liquid}$ Dentin. ${ }^{(39)}$ These results agree with those of Poitevin et al., 2013 ${ }^{(51)}$ and Fu et al., 2013 ${ }^{(52)}$ in respect to Vertise Flow. It was reported, in that studies, that 
the high acidity of Vertise Flow leads to opening the dentinal tubules and exposes the collagen network, which is similar to the effect of etch-and-rinse method using phosphoric acid. The fewer discrete resin tags that are observed in scanning electron micrographs of Fusio Liquid Dentin sections may also be due to the path of sectioning was parallel to the dentinal tubules. ${ }^{(53)}$ However, the minute gaps that were noticed in the image (Fig. 1d) of OptiBond All-In-One at adhesive-composite interface might be due to the incomplete polymerization of resin due to presence of residual water, as residual water may be retained due to its low vaporization in the presence of HEMA. ${ }^{(54)}$

\section{CONCLUSION}

Within the limitations of this in vitro study it can be concluded that the new self-adhering flowable composites ( Vertise Flow, Dyad Flow, Fusio Liquid Dentin) achieved statistically similar micro-shear bond strength to dentin, which were comparable to that obtained with a combination of all-in-one adhesive and conventional flowable composite (Optibond All-In-One + Premise Flowable). All materials tested exhibited a continuous interface and appeared well-adapted to dentin substrate. However, additional investigation under clinical conditions are required to confirm the results achieved from this in-vitro study.

\section{REFERENCES}

1. Viadyanathan TK, Viadyanathan J. Recent advances in the theory and mechanism of adhesive resin bonding to dentin: a critical review. J Biomed Mater Res B Appl Biomater 2009;88:558-578.

2. Vichi A, Margvelashvili M, Goracci C, Papacchini F, Ferrari M. Bonding and sealing ability of a new self-adhering flowable composite resin in class I restorations. Clin Oral Invest 2013;17:1497-1506.

3. Mac YF, Lia SC, Cheung GS, Chan AW, Tay FR, Pashley DA. Micro-tensile bond testing of resin cements to dentin and an indirect resin composite. Dent Mater 2002;18:609-621.
4. Ilie N, Hickel R. Resin composite restorative materials. Aust Dent J 2011;56(Suppl I):59-66.

5. Moszner N, Salz U, Zimmermann J. Chemical aspects of self-etching enamel-dentin adhesives: a systemic review. Dent Mater 2005;21:895-910.

6. De Munck J, Van Landuyt K, Peumans M, Poitevin A, Lambrechts P, Braem M, Van Meerbeek BA. A critical review of the durability of adhesion to tooth tissue: methods and results. J Dent Res 2005; 84:118-132.

7. Van Meerbeek B, Van Landuyt KL, De Munck J, Hashimoto M, Peumans M, Lambrechts P, Poitevin A, Yoshida Y, Inoue S, Suzuki K. Technique-sensitivity of contemporary adhesives. Dent Mater 2005;24:1-13.

8. Van Landuyt KL, De Munck J, Snauwaert J, Coutinho E, Poitevin A, Yoshida Y, Inoue S, Peumans M, Suzuki K, Lambrechts P, Van Meerbeek B. Monomer-solvent phase separation in one-step self-etch adhesives. J Dent Res 2005;84:183-188.

9. Perdigao J, Gomes G, Gondo R, Fundingsland JW. In vitro bonding performance of all-in-one adhesives. Part I - microtensile bond strength. J Adhes Dent 2006;8:367-373.

10. Van Landuyt KL, Peumans M, De Munck J, Lambrechts P, Van Meerbeek B. Extension of a one-step self-etch adhesive into a multi-step adhesive. Dent Mater 2006;22:533544.

11. Van Landuyt KL, Snauwaert J, De Munck J, Coutinho E, Poitevin A, Yoshida Y, Suzuki K, Lambrechts P, Van Meerbeek B. Origin of interfacial droplets with one-step adhesives. J Dent Res 2007;86:739-744.

12. Finger WJ, Shao B, Hofmann M, Endo T, Komatsu M. Does application of phase-separated self-etching adhesives affect the bond strength? J Adhes Dent 2007;9:169-173.

13. Pashley DH, Tay FR. Aggressiveness of contemporary self-etching adhesive. Part II: etching effects on unground enamel. 2001;17:296-308.

14. Tay FR, Gwinnett AJ, Pang KM, Wei SH. Resin permeation into acid-conditioned, moist, and dry dentin: a paradigm using water-free adhesive primers. 1996;75:10341044 .

15. Tay FR, Gwinnett AJ, Wei SH. Micromorphological spectrum from overdrying to overwetting acid-conditioned dentin in water-free acetone-based, single-bottle primer/ adhesives. 1996;12:236-244. 
16. Goracci C, Margvelashvili M, Giovannetti A, Vichi A, Ferrari M. shear bond strength of orthodontic brackets bonded with a new self-adhering flowable resin composite. Clin Oral Invest 2013;17:609-617.

17. Bayne SC, Thompson JY, Swift EJ Jr, Stamatiades P, Wilkerson M. A. characterization of first-generation flowable composites. J Am Dent Assoc 1998;50:567-577.

18. Alonso RC, Sinhoreti MA, Correr Sobriho L, Consani $\mathrm{S}$, Goes MF. Effect of resin liners on the microleakage of class V dental composite restorations. J Appl Oral Sci 2004;12:56-61.

19. Helvatjoglu-Antoniades M, Papadogiannis Y, Lakes RS, Dionysopoulos P, Papadogiannis D. Dynamic and static elastic moduli of pakable and flowable composite resins and their development after initial photo curing. Dent Mater 2006;22:450-459.

20. Unterbrink GL, Liebenberg WH. Flowable resin composites as filled adhesives: literature review and clinical recommendation. Quintessence Int 1999;30:249-257.

21. Labella R, Lambrechts P, Van Meerbeek B, Vanherle G. Polymerization shrinkage and elasticity of flowable composites and filled adhesives. Dent Mater 1999;15:128-137.

22. Estafan D, Estafan A, Leinfelder KF. Cavity wall adaptation of resin-based composite lined with flowable composite. Am J Dent 2000;13:195-2-194.

23. Attar N, Tam LE, McComb D. Flow, strength, stiffness and radiopacity of flowable resin composite. J Can Dent Assoc 2003;69:516-521.

24. Chuang SF, Liu KJ, Chao CC, Liao FP, Chen YH. Effects of flowable composite lining and operator experience on microleakage and internal voids in class II composite restorations. J Prosthet Dent 2001;85:117-183.

25. Baroudi KN, Silikas N, Watts DC. Time-dependent viscoelastic creep and recovery of flowable composites. Eur J Oral Sci 2007; 115:517-521.

26. He Z, Shimada Y, Ikeda M, Tagami J. The effects of cavity size and filling method on the bonding to class I cavities. J Adhes Dent 2008;10:447-453.

27. Yoshikawa T, Sano H, Burrow MF, Tagamin J, Pashley DH. Effect of dentin depth and cavity configuration on bond strength. J Dent Res 1999;78:898-905.

28. Sadeghi M. An in vitro microleakage study of class $\mathrm{V}$ cavities restored with a new self-adhesive flowable composite resin versus different flowable materials.
29. VanMeerbeek B, Yoshihara K, Yoshida Y, Mine A, De Munck I, Van Landyut KL. State of the art of self-etch adhesives. Dent Mater 2011;27:17-28.

30. Rengo C, Goracci C, Juloski J, Chieffi N, Giovannetti A, Vichi A, Ferrari M. influence of phosphoric acid etching on microleakage of a self-etch adhesive and a self-adhering composite. Aust Dent J 2012;57:220-226.

31. Nakabayashi N, Takarada K. Effect of HEMA on bonding to dentin. 1992;8:125-130.

32. Cavalcanti AN, De Souza ES, Lopes GDS, De Freitas AP, De Araújo RPC, Mathias P. Effect of a desensitizing dentifrice on the bond strength of different adhesive systems. Braz J Oral Sci. 2013;12:2.

33. Menezes FCH, Borges GA, Valentino TA, Oliveira MAHM, Turssi CP, Correr-Sobrinho L. Effect of surface treatment and storage on the bond strength of different ceramic systems. Braz J Oral Sci. 2009; 8: 119-23.

34. Koliniotou-Koumpia E, Kouros P, Koumpia E, Helvatzoglou-Antoniades M. Shear bond strength of a "solventfree" adhesive versus contemporary adhesive systems. Braz J Oral Sci 2014;13.

35. Yoshida Y, Nagakane K, Fukuda R, Nakayama Y, Okazaki $\mathrm{M}$, Shintani $\mathrm{H}$ et al. Comparative study on adhesive performance of functional monomers. J Dent Res. 2004; 83: 454-8.

36. Ikemura K, Kadoma Y, Endo T. A review of the developments of self-etching primers and adhesives. Effects of acidic adhesive monomers and polymerization initiators on bonding to ground smear layer-covered teeth. Dent Mater. J 2012; 30: 769-89.

37. Kerr. Vertise Flow: self-adhering flowable composite. Available at: http:/www.kerrdental.com/index/kerrdentalcomposites-vertiseflow-2. Accessed August 2015.

38. Kerr product manual. Dyad flow self-adhering flowable composite. 2009.

39. Pentron Clinical, Fusio Liquid Dentin. Available at: http:/ www. index.php/products/product_detail/fusio_liquid_ dentin. Accessed August 2015.

40. OptiBond All-In-One adhesive. Available at https://www. kerrdental.com/kerr-restoratives/optibond-all-one-singlecomponent-self-etch-dental-adhesive. Accessed August 2015.

41. Van Landuyt KL, Snauwaert J, Peumans M, De Munck J, Coutinho Lambrechts P, Van Meerbeek B. The role of HEMA in one-step self-etch adhesives. Dent Mater 2008; 24:1412-1419. 
42. Sidhu SK, Omata Y, Tanaka T, Koshiro K, Spreafico D, Semeraro S, Mezzanzanica D, Sano H. Bonding characteristics of newly developed all-in-one adhesives. 2007; $80: 29303$.

43. Celik EU, Kucukyilmaz E, Savas S. Effect of different surface pre-treatment methods on the microleakage of two different self-adhesive composites in class V cavities. Europ J Pediat Dent 2015;16:33-38.

44. Kurtzman GM, Afrashtehfar KI. Dyad Flow: a self-etch flowable composite $1^{\text {st }}$ part. Available at http://www.researchgate.net/publication/262726 dyad flow a self-etch flowable composite 1 st part

45. Tuloglu N, Tunk ES, Ozer S, Bayrak S. Shear bond strength of self-adhering flowable composite on dentin with and without application of an adhesive system. J Appl Biomater Funct Mater 2014;12:97-101.

46. Wei YG, Silikas N, Zahang ZT, Watts DC. Hygroscopic dimensional changes of self-adhering and new-resin matrix composites during water sorption/desorption cycles. Dent Mater 2011;27:259-266.

47. Wei YG, Silikas N, Zahang ZT, Watts DC. Diffusion and concurrent solubility of self-adhering and new-resin matrix composites during water sorption/desorption cycles. Dent Mater 2011;27:197-205.

48. Hirasawa T, Hirano S, Hirabayashi S, Harashima I, Aizawa M. Initial dimensional change of composites in dry and wet conditions. J Dent Res 1983;62:28-31.

49. Hosaka K, Nakajima M, Takahashi M, Itoh S, Ikeda M, Tagami J, Pashley DH. Relationship between mechanical properties of one-step self-etch adhesives and water sorption. Dent Mater 2010;26:360-367.

50. Davidson CL, Feilzer AJ. Polymerization shrinkage and Polymerization shrinkage stress in polymer-based restoratives. 1997;25:435-440.

51. Poitevin A, De Munck J, Van Ende A, Suyama Y, Mine A, Peumans M, Van Meerbeek B. Bonding effectiveness of self-adhesive composites to dentin and enamel. Dent Mater 2013;29:221-230.

52. Fu J, Kakuda S, Pan F, Hishika S, Ting S, Fukuoka A, Bao Y, Ikeda T, Nakaoki Y, Selimovic D, Sano H, Sidhu SK. Bonding performance of a newly developed step-less all-in one system on dentin. Dent Mater 2013;32:203-211.

53. Mortazavi V, Fathi M, Ataei E, Khodaeian N, Askari N. Shear bond strengths and morphological evaluation of filled and unfilled adhesive interfaces to enamel and dentine. International J Dent, Volume 2012, Article ID 858459. Available at http://dx.doi.org/10.1155/2012/858459. Accessed August 2015.

54. Abo El Naga A, Yousef N, Ramadan R, Bahgat SF, Alshawwa L. Does the use of a novel self-adhesive flowable composite reduce nanoleakage? Clin Cosmet Investig Dent 2015;7:55-64. 